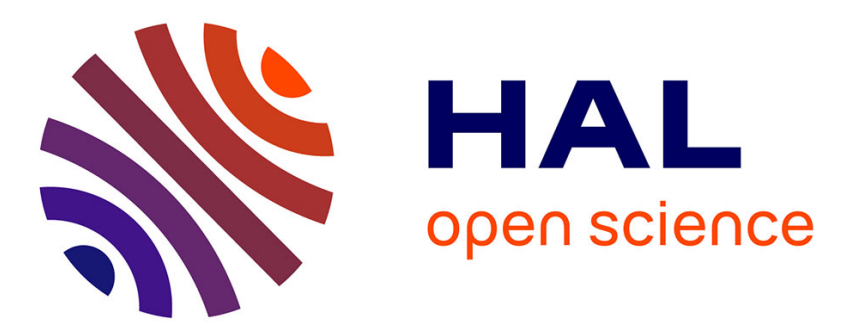

\title{
Synthesis, characterization and magnetism of homoleptic bis(5-aryl-2-iminopyrrolyl) complexes of iron(II) and cobalt(II)
}

Tiago F.C. Cruz, Cláudia A Figueira, João C Waerenborgh, Laura C.J. Pereira, Yianling Li, Rodrigue Lescouëzec, Pedro Gomes

\section{To cite this version:}

Tiago F.C. Cruz, Cláudia A Figueira, João C Waerenborgh, Laura C.J. Pereira, Yianling $\mathrm{Li}$, et al.. Synthesis, characterization and magnetism of homoleptic bis(5-aryl-2-iminopyrrolyl) complexes of iron(II) and cobalt(II). Polyhedron, 2018, 152 (Septembre 2018), pp.179-187. 10.1016/j.poly.2018.06.026 . hal-01958650

\section{HAL Id: hal-01958650 https://hal.sorbonne-universite.fr/hal-01958650}

Submitted on 18 Dec 2018

HAL is a multi-disciplinary open access archive for the deposit and dissemination of scientific research documents, whether they are published or not. The documents may come from teaching and research institutions in France or abroad, or from public or private research centers.
L'archive ouverte pluridisciplinaire HAL, est destinée au dépôt et à la diffusion de documents scientifiques de niveau recherche, publiés ou non, émanant des établissements d'enseignement et de recherche français ou étrangers, des laboratoires publics ou privés. 


\title{
Synthesis, characterization and magnetism of homoleptic bis(5-aryl-2-iminopyrrolyl) complexes of iron(II) and cobalt(II)
}

\author{
Tiago F. C. Cruz ${ }^{\mathrm{a}}$, Cláudia A. Figueira ${ }^{\mathrm{a}}$, João C. Waerenborgh ${ }^{\mathrm{b}}$, Laura C. J. Pereira ${ }^{\mathrm{b}}$, \\ Yianling Li ${ }^{\mathrm{c}}$, Rodrigue Lescouëzec ${ }^{\mathrm{c}}$, Pedro T. Gomes ${ }^{\mathrm{a}, *}$
}

a Centro de Química Estrutural, Departamento de Engenharia Química, Instituto Superior Técnico, Universidade de Lisboa, Av. Rovisco Pais 1, 1049-001 Lisboa, Portugal.

b $C^{2} T N-C e n t r o$ de Ciências e Tecnologias Nucleares, Instituto Superior Técnico, Universidade de Lisboa, 2695-066 Bobadela LRS, Portugal.

c Sorbonne Université, Institut Parisien de Chimie Moléculaire, IPCM, CNRS UMR 8232, 4 place Jussieu, 75252 Paris, France.

* Corresponding author; Tel: +3518419612; E-mail: pedro.t.gomes@ tecnico.ulisboa.pt

\begin{abstract}
Four sterically congested and highly electronically unsaturated bis(5-aryl-2iminopyrrolyl) $\mathrm{ML}_{2}$ complexes of $\mathrm{Fe}(\mathrm{II})$ and $\mathrm{Co}(\mathrm{II}),\left[\mathrm{M}\left\{\kappa^{2} N, N-5-\left(2,6-\mathrm{R}_{2}-\mathrm{C}_{6} \mathrm{H}_{3}\right)-\mathrm{NC}_{4} \mathrm{H}_{2}-2-\right.\right.$ $\left.\left.\mathrm{C}(\mathrm{H})=\mathrm{N}\left(2,6-{ }^{\mathrm{i}} \mathrm{Pr}_{2}-\mathrm{C}_{6} \mathrm{H}_{3}\right)\right\}_{2}\right](\mathrm{M}=\mathrm{Fe}, \mathrm{R}=\mathrm{H}(\mathbf{1 a}) ; \mathrm{M}=\mathrm{Fe}, \mathrm{R}=\mathrm{Me}(\mathbf{1 b}) ; \mathrm{M}=\mathrm{Co}, \mathrm{R}=\mathrm{H}(\mathbf{2} \mathbf{a})$; $\mathrm{M}=\mathrm{Co}, \mathrm{R}=\mathrm{Me}(\mathbf{2} \mathbf{b}))$, were synthesized by metathetic reaction of the in situ prepared sodium salts of the new 5-aryl-2-( $N$-2,6-diisopropylformimino)pyrrole HL type ligand precursors $(\mathrm{R}=\mathrm{H}(\mathbf{I a})$, Me $(\mathbf{I b}))$ with $\mathrm{FeCl}_{2}$ or $\mathrm{CoCl}_{2}$, in moderate to good yields. The fourcoordinate complexes were characterized by elemental analysis, X-ray diffraction, magnetic susceptibility measurements in solution and in solid state, and ${ }^{57} \mathrm{Fe}$ Mössbauer spectroscopy. All complexes have a high-spin electronic configuration, as measured both in solution, through the Evans method, and in solid state, through SQUID magnetic measurements, and Mössbauer spectroscopy for the case of $\mathrm{Fe}(\mathrm{II})$ complexes, displaying a tetracoordinated distorted tetrahedral coordination geometry about the respective metal center, as elucidated by X-ray diffraction. The inclusion of ortho-methyl groups in the 5-phenyl substituent of the 2-iminopyrrolyl ring in complexes $\mathbf{1 b}$ and $\mathbf{2 b}$ has an important influence in the structure of the complexes, giving rise to pronounced geometry distortions in particular for $\mathbf{1 b}$. This complex exhibits a see-saw-like geometry whereas a pyramidalization of the pyrrolyl nitrogen is observed for $\mathbf{2} \mathbf{b}$. Overall, the magnetic properties of the complexes can be rationalized by taking into account the effect of the magnetic anisotropy arising from the
\end{abstract}


second-order spin orbit coupling and the geometrical distortion. The simulation of the magnetic data using a zero-field splitting (ZFS) Hamiltonian led to values of the axial anisotropy, $D$, that are coherent for $\mathrm{Co}$ (II) and Fe(II) tetrahedral complexes, $D \approx-50 \mathrm{~cm}^{-1}$ (2a), 2b) and $4 \mathrm{~cm}^{-1}(\mathbf{1 a})$. In the case of $\mathbf{1 b}$ the simulation evidenced a strong magnetic anisotropy with both axial and rhombic contributions $\left(D \approx-50 \mathrm{~cm}^{-1}, E \approx 10 \mathrm{~cm}^{-1}\right)$ which are in line with the strongly distorted coordination sphere of the complex.

Keywords: 5-aryl-2-iminopyrrolyl ligands; four-coordinate complexes; Iron(II); Cobalt(II); structure and magnetic properties 


\section{Introduction}

The chemistry of transition metals bearing bidentate ligands is of paramount importance in catalysis, for the most diverse transformations, as well as in materials science. In recent years, the use of earth-abundant metals instead of the platinum group elements has been a priority. Despite the clear economical advantage of earth-abundant metals, their low-coordinate heteroleptic chemistry with bidentate scaffolds remains relatively unexplored and somewhat unpredictable. For example, attempts to prepare low-valent or alkyl Fe and Co compounds of a single bidentate ligand led to disproportionation products of bis bidentate ligand metal compounds [1]. Despite the catalytic inactivity of these and other examples, homoleptic compounds of $\mathrm{Fe}$ and $\mathrm{Co}$ of bidentate ligands have still been attractive to other fields, such as magnetochemistry $[2,3]$.

The chemistry of the bis bidentate 2-iminopyrrolyl framework has been modestly covered in the coordination chemistries of main-group elements, such as alkaline-earth metals $(\mathrm{Mg}$, $\mathrm{Ca}, \mathrm{Sr}, \mathrm{Ba}$ ) [4,5] or Al [4], of early transition metals (Zr [6], Ti [7], V [8] and Cr [9]) and of late transition metals ( $\mathrm{Ni}[6,10-12], \mathrm{Cu}[10,11]$ and $\mathrm{Zn}[4,13])$. However, this simple scaffold is somehow reminiscent of porphyrins, which play a major role as ligands to biochemically relevant metals, such as Fe [14] and Co [15].

Specifically concerning the chemistry of Fe and Co bearing two 2-iminopyrrolyl bidentate ligands, to the best of our knowledge, only Bochmann et al. and our group have presented results with aryl substituents bonded to the iminic nitrogen atom. On one hand, Bochmann and co-workers reported bis bidentate bis(arylimino)pyrrolyl compounds of $\mathrm{Fe}(\mathrm{II})$ and $\mathrm{Co}(\mathrm{II})$, prepared from the 2,5-bis(arylimino)pyrrole ligand precursor $\mathrm{HNC}_{4} \mathrm{H}_{2}-2,5-\left[\mathrm{CH}=\mathrm{N}\left(2,6-{ }^{i} \mathrm{Pr}_{2}-\right.\right.$ $\left.\left.\mathrm{C}_{6} \mathrm{H}_{3}\right)\right]_{2}$ [6]. On the other hand, we have also prepared and characterized a series of $\mathrm{Co}(\mathrm{II})$ unsaturated (15-electron) homoleptic complexes of the type [Co $\left\{2-(N \text {-arylimino)pyrrolyl }\}_{2}\right]$, whereby tuning the steric bulkiness of the 2-aryliminopyrrolyl ligand, different coordination geometries of the $\mathrm{Co}$ (II) center were obtained, from tetrahedral (Chart 1, A) to the rarely observed square planar (Chart 1, B) [16]. In a different work, our group reported the unsuccessful attempts to prepare four-coordinate $\mathrm{Fe}(\mathrm{II})$ compounds of the type $[\mathrm{Fe}(2-(\mathrm{N}-$ arylimino)pyrrolyl) 2 ], which were isostructural with $\mathbf{A}$, ending up in uncharacterized products or in $\mathrm{Fe}$ (III) oxo complexes, the latter resulting from the oxidation of those highly reactive $\mathrm{Fe}$ (II) species with adventitious water molecules, owing to their unsaturated nature (14electron species) [11]. In fact, the stabilization of those unsaturated species was achieved by 
the simple addition of a donor ligand, such as pyridine, to the reaction medium, yielding the expected five-coordinate 16-electron Fe(II) complex (Chart 1, C) [11]. Similar pentacoordinated complexes of $\mathrm{Co}(\mathrm{II})$, containing the bis(2-formiminopyrrolyl) framework and a donor ligand, had been obtained with trimethylphosphine and tetrahydrofuran (Chart 1, C), but could only be prepared from the substitution reaction of the corresponding cobalt halide adducts $\left(\left[\mathrm{CoCl}_{2}\left(\mathrm{PMe}_{3}\right)_{2}\right]\right.$ and $\left.\left[\mathrm{CoCl}_{2}(\mathrm{THF})_{1.5}\right]\right)$ with 2 equivalents of the 2iminopyrrolyl sodium salt, but not from the addition of $\mathrm{PMe}_{3}$ or THF to complexes of the type $\mathbf{A}$ [17].

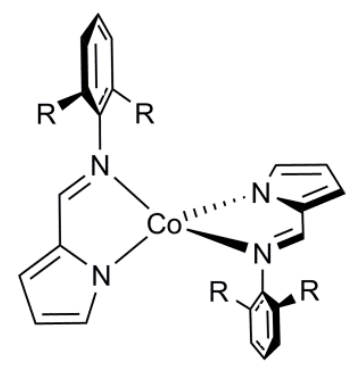

A

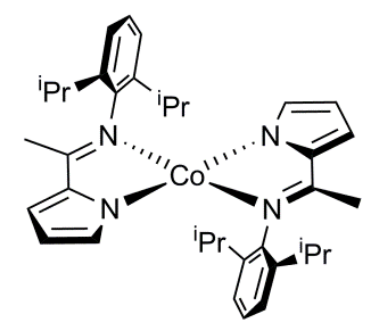

B

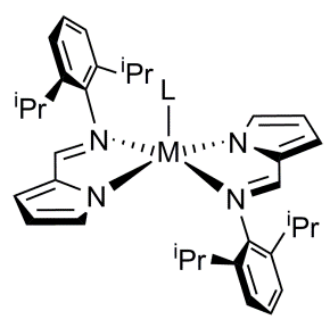

C

$\mathrm{M}=\mathrm{Fe}, \mathrm{L}=\mathrm{Py}$

$\mathrm{M}=\mathrm{Co}, \mathrm{L}=\mathrm{THF}, \mathrm{PMe}_{3}$

Chart 1

In the present work, we report the employment of sterically congested new 2-(Narylformimino)pyrrole ligand precursors, which are substituted in position 5 of the pyrrole ring with phenyl rings (Scheme 1), in order to confer steric protection to the metal center and prepare stable highly unsaturated homoleptic Fe(II) bis(5-aryl-2-formiminopyrrolyl) complexes. We also describe the synthesis of the related homoleptic Co(II) bis(5-aryl-2formiminopyrrolyl) complexes in order to compare their structure and properties with the previously reported analogous unsubstituted $\mathrm{Co}$ (II) bis(2-formiminopyrrolyl) complexes. ${ }^{[16]}$ Both types of compounds are characterized by elemental analysis, single crystal X-ray diffraction, magnetic measurements in solution and in the solid state and ${ }^{57} \mathrm{Fe}$ Mössbauer spectroscopy. 


\section{Results and discussion}

\subsection{Syntheses of the ligand precursors and complexes}

The new 5-aryl-2-( $N$-2,6-diisopropylformimino)pyrrole HL type ligand precursors used in this work were prepared in good yields ( $c a .70-90 \%)$ from the catalytic condensation reaction of the previously reported 5-aryl-2-formyl-1H-pyrroles [18] with 2,6-diisopropyl aniline, in refluxing toluene (Scheme 1).
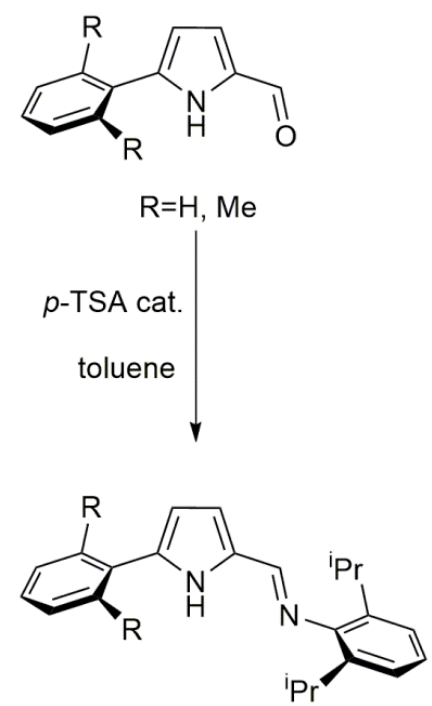

la $\mathrm{R}=\mathrm{H}$

Ib $\mathrm{R}=\mathrm{Me}$
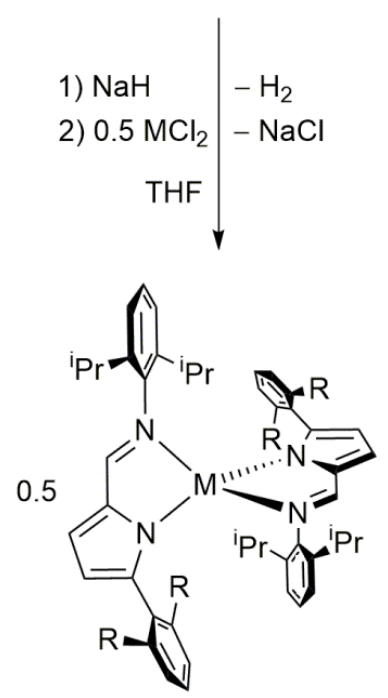

1a $\mathrm{M}=\mathrm{Fe}, \mathrm{R}=\mathrm{H}$

1b $\mathrm{M}=\mathrm{Fe}, \mathrm{R}=\mathrm{Me}$

2a $\mathrm{M}=\mathrm{Co}, \mathrm{R}=\mathrm{H}$

2b $\mathrm{M}=\mathrm{Co}, \mathrm{R}=\mathrm{Me}$

Scheme 1 Synthesis of the new 5-aryl-2-(N-2,6-diisopropylformimino)pyrrole ligand precursors and their corresponding Fe and Co complexes. 
The corresponding homoleptic $\mathrm{ML}_{2}$ complexes were synthetized in moderate to good yields by the salt metathesis of $\mathrm{MCl}_{2}$, where $\mathrm{M}$ is $\mathrm{Fe}$ or $\mathrm{Co}$, with two equivalents of the sodium salt of the respective ligand precursor (Ia or Ib) prepared in situ in a THF solution. After a standard work-up procedure, a $n$-hexane solution cooled to $-20{ }^{\circ} \mathrm{C}$ yielded orange-red crystals of the Fe(II) complexes 1a and 1b. The Co(II) complexes were obtained in a similar procedure, yielding dark red-green and dark red-brown crystals, respectively for $\mathbf{2 a}$ and $\mathbf{2 b}$. (Scheme 1). These complexes were characterized by elemental analysis, single crystal X-ray diffraction, ${ }^{1} \mathrm{H}$ NMR spectroscopy, magnetic susceptibility measurements in solution and in the solid state, and Mössbauer spectroscopy for the case of the Fe(II) compounds.

The four complexes are soluble in $n$-hexane and show no signs of decomposition after heating their toluene solutions to $100{ }^{\circ} \mathrm{C}$ for $24 \mathrm{~h}$, under dinitrogen. These compounds are relatively stable in the crystalline state but their respective solutions are sensitive to air and moisture.

All complexes are paramagnetic and the $\mathrm{Fe}$ and Co centers are quite unsaturated, formally having 14 and 15 valence electrons, respectively. Magnetic susceptibility measurements in toluene- $d_{8}$ solutions of the Fe complexes $1 \mathbf{a}$ and $\mathbf{1 b}$ led to solution magnetic moments of 5.9 and 5.6 $\mu_{\mathrm{B}}$, respectively, as determined by the Evans method. On the other hand, using the same method, the Co complexes $\mathbf{2 a}$ and $\mathbf{2 b}$ display solution magnetic moments of 4.8 and 5.0 $\mu_{\mathrm{B}}$, respectively. These observations are in accordance with high-spin configurations of $\mathrm{d}^{6}$ Fe(II) centers $\left(S=2 ; \mu_{e f f}=4.9 \mu_{\mathrm{B}}\right)$ and $\mathrm{d}^{7} \mathrm{Co}(\mathrm{II})$ centers $\left(S=3 / 2 ; \mu_{\text {eff }}=3.88 \mu_{\mathrm{B}}\right)$, with spinorbit coupling [16,19,20].

The complexes show paramagnetically shifted ${ }^{1} \mathrm{H}$ NMR spectra, ranging from 120 to -60 ppm in the most extreme cases. A striking difference is observed in the ${ }^{1} \mathrm{H}$ NMR spectra of complexes 1a-2a $(\mathrm{R}=\mathrm{H})$ and $\mathbf{1 b}-\mathbf{2} \mathbf{b}(\mathrm{R}=\mathrm{Me})$ (the ${ }^{1} \mathrm{H}$ NMR spectra of the complexes are presented in Figs. S1-S4 of the Supplementary data). Complexes 1a-2a show a set of resonances corresponding to a single 5-aryl-2-iminopyrrolyl moiety, indicating a $C_{2}$ symmetry, explained by the free rotation of the pyrrolyl 5-substituted phenyl rings. On the other hand, complexes $\mathbf{1 b}-\mathbf{2 b}$ show a much higher number of resonances than expected for two magnetically equivalent 5-aryl-2-iminopyrrolyl moieties, hence displaying a $C_{1}$ symmetry. This difference is attributed to the hindered rotation generated by steric repulsion of the ortho-methyl groups of the 5-phenyl substituent of the pyrrolyl ring.

There are also marked differences in the solid-state structures of complexes 1a-2a and 1b$\mathbf{2 b}$, obtained by single crystal X-ray diffraction. 


\subsection{X-ray diffraction studies}

All complexes were obtained as crystals suitable for X-ray diffraction from concentrated $n$ hexane solutions cooled to $-20^{\circ} \mathrm{C}$. Complexes 1a-2a and $\mathbf{1 b}-\mathbf{2 b}$ crystallized in the triclinic and monoclinic crystal systems, in the $\mathrm{P}-1$ and $\mathrm{P} 2{ }_{1} / \mathrm{c}$ space groups, respectively. The structures obtained by X-ray diffraction are displayed in Fig. 1, and a selection of bond lengths, bond angles and $\tau_{4}$ parameters ( 0 for square planar and 1 for tetrahedral pure geometries) [21] of the structures are shown in Table 1. The crystallographic data of the compounds is presented in Table S1 of the Supplementary data.

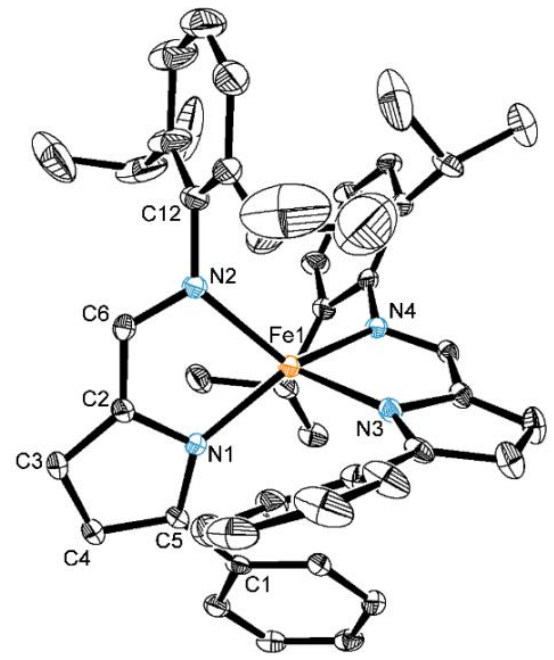

1a

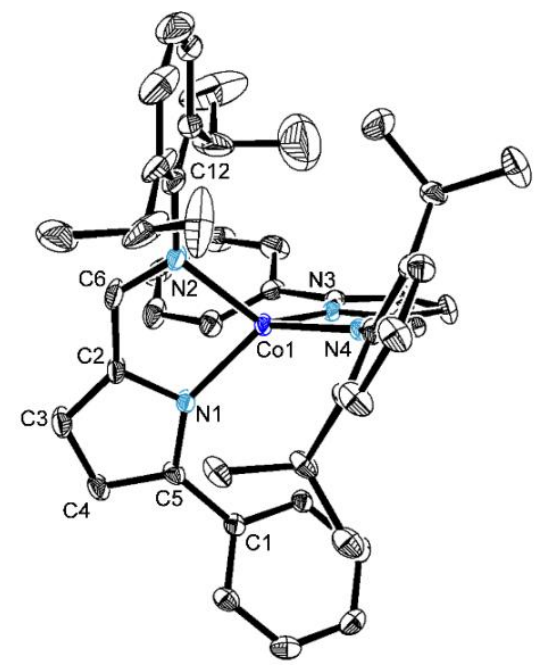

2a

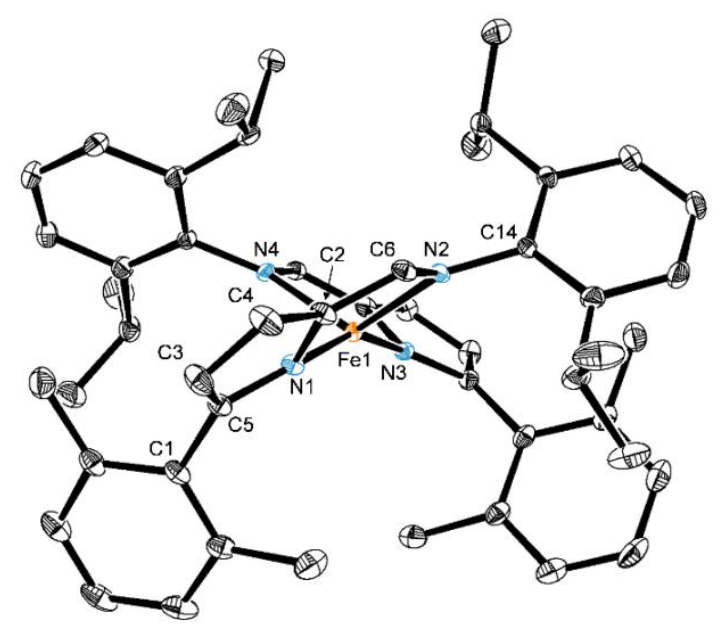

1b

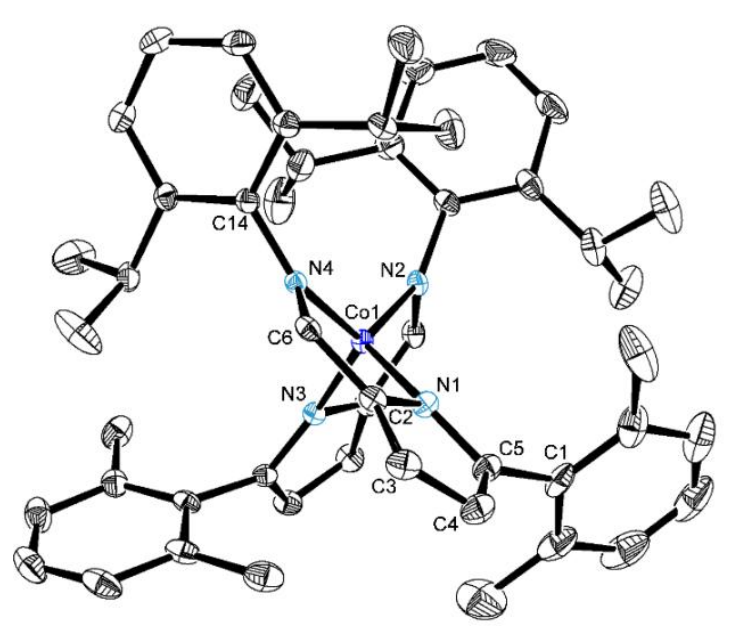

2b

Fig. 1 ORTEP-3 diagrams of the X-ray diffraction structures of all four complexes, showing 30\% probability ellipsoids. Hydrogen atoms are omitted for clarity. 
Table 1 Selected bond distances $(\AA)$ and bond angles $\left({ }^{\circ}\right)$ for all complexes.

\begin{tabular}{|c|c|c|c|c|}
\hline & $1 \mathbf{a}$ & 1b & $2 \mathbf{a}$ & $2 b$ \\
\hline \multicolumn{5}{|l|}{ Distances $(\AA)$} \\
\hline M1-N1 & $2.009(4)$ & $2.0160(18)$ & $1.976(3)$ & $1.9899(18)$ \\
\hline M1-N3 & $2.024(4)$ & $2.0157(18)$ & $1.983(3)$ & $1.9990(18)$ \\
\hline M1-N2 & $2.065(4)$ & $2.1505(19)$ & $2.037(3)$ & $2.0306(17)$ \\
\hline M1-N4 & $2.062(4)$ & $2.1456(18)$ & $2.039(4)$ & $2.0392(18)$ \\
\hline N1-C5 & $1.359(6)$ & $1.364(3)$ & $1.355(5)$ & $1.351(3)$ \\
\hline N1-C2 & $1.389(6)$ & $1.385(3)$ & $1.384(5)$ & $1.386(3)$ \\
\hline N2-C6 & $1.301(6)$ & $1.303(3)$ & $1.302(5)$ & $1.307(3)$ \\
\hline $\mathrm{N} 2-\mathrm{C}_{\mathrm{ipso}}$ & $1.430(6)$ & $1.442(3)$ & $1.433(5)$ & $1.435(3)$ \\
\hline $\mathrm{C} 1-\mathrm{C} 5$ & $1.475(7)$ & $1.481(3)$ & $1.474(6)$ & $1.489(3)$ \\
\hline C2-C3 & $1.392(7)$ & $1.396(3)$ & $1.389(6)$ & $1.400(3)$ \\
\hline C2-C6 & $1.405(7)$ & $1.411(3)$ & $1.407(6)$ & $1.408(3)$ \\
\hline $\mathrm{C} 3-\mathrm{C} 4$ & $1.388(7)$ & $1.388(4)$ & $1.391(6)$ & $1.388(4)$ \\
\hline C4-C5 & $1.395(7)$ & $1.399(3)$ & $1.395(6)$ & $1.402(3)$ \\
\hline \multicolumn{5}{|l|}{ Angles $\left({ }^{\circ}\right)$} \\
\hline N1-M1-N3 & $118.22(16)$ & $155.74(7)$ & $119.02(14)$ & $114.90(7)$ \\
\hline N1-M1-N2 & $83.38(16)$ & $82.51(7)$ & 83.83(13) & $84.15(7)$ \\
\hline N3-M1-N2 & $127.49(16)$ & $105.97(7)$ & $127.12(14)$ & $126.23(7)$ \\
\hline N1-M1-N4 & $130.15(19)$ & $111.60(7)$ & $128.66(17)$ & $125.01(7)$ \\
\hline N3-M1-N4 & $83.23(16)$ & $82.06(7)$ & 83.91(14) & $85.11(7)$ \\
\hline N2-M1-N4 & $120.37(16)$ & $126.43(7)$ & $120.00(14)$ & $125.95(7)$ \\
\hline $\mathrm{C} 5-\mathrm{N} 1-\mathrm{C} 2$ & $106.2(4)$ & $106.60(19)$ & $107.0(3)$ & $106.68(18)$ \\
\hline C6-N2-C & $120.0(4)$ & $118.7(2)$ & 119.2(3) & $119.22(17)$ \\
\hline N1-C2-C3 & $109.9(4)$ & $109.8(2)$ & $109.7(4)$ & $109.76(19)$ \\
\hline N1-C2-C6 & $117.5(4)$ & $119.0(2)$ & $117.6(4)$ & $116.89(18)$ \\
\hline C3-C2-C6 & $132.4(4)$ & $131.2(2)$ & $132.5(4)$ & $133.0(2)$ \\
\hline C2-C3-C4 & $106.4(5)$ & $106.4(2)$ & $106.2(4)$ & $106.2(2)$ \\
\hline C3-C4-C5 & $107.4(5)$ & $107.6(2)$ & $107.7(4)$ & $107.4(2)$ \\
\hline N1-C5-C4 & $110.1(4)$ & $109.6(2)$ & $109.4(4)$ & $110.0(2)$ \\
\hline $\mathrm{N} 1-\mathrm{C} 5-\mathrm{C} 1$ & $121.8(5)$ & $123.0(2)$ & $122.6(4)$ & $122.1(2)$ \\
\hline $\mathrm{C} 4-\mathrm{C} 5-\mathrm{C} 1$ & $128.2(5)$ & $127.2(2)$ & $127.9(4)$ & $127.1(2)$ \\
\hline N2-C6-C2 & $120.5(4)$ & $120.7(2)$ & $119.0(3)$ & 119.96(19) \\
\hline$\tau_{4}$ & 0.73 & 0.55 & 0.74 & 0.76 \\
\hline
\end{tabular}


Complexes 1a-2a are tetracoordinated entities, where two 5-phenyl-2-iminopyrrolyl ligands are coordinated to the metal center in a bidentate mode through the iminic (N2 and N4) and pyrrolyl (N1 and N3) nitrogen atoms in distorted tetrahedral geometries. The chelate bite angles in these complexes i.e. the $\mathrm{N} 1-\mathrm{M}-\mathrm{N} 2$ are very similar in both structures $\left(83.33(13)-83.38(16)^{\circ}\right)$. On the other hand, the $\mathrm{N} 1-\mathrm{M}-\mathrm{N} 3$ and $\mathrm{N} 2-\mathrm{M}-\mathrm{N} 4$ angles are 118.22(16)-119.02(14) ${ }^{\mathrm{o}}$ and $120.00(14)-120.37(16)^{\mathbf{o}}$, respectively for complexes $\mathbf{1 a}$ and $\mathbf{2 a}$, pointing to a distorted tetrahedral geometry $\left(\tau_{4}=0.73-0.74\right)$. The $\mathrm{M}-\mathrm{N} 1$ and $\mathrm{M}-\mathrm{N} 2$ bond lengths are also close: 2.009(4)-2.065(4) $\AA$ in the Fe complex 1a and 1.976(3)-2.039(4) $\AA$ in the Co complex 2a. The angles between the planes corresponding to the five membered chelates are 81.1 and $82.2^{\circ}$ for $\mathbf{1 a}$ and $\mathbf{2 a}$, respectively. These observations are in accordance with the structural data of homoleptic bis(2-iminopyrrolyl) Co(II) compounds reported previously by our group, which were unsubstituted in position 5 of the pyrrolyl ring [16]. The torsions of the 2,6-diisopropylphenyl ring (bonded to the iminic nitrogen) relative to the 2iminopyrrolyl moieties are in the range of $64.54-74.08^{\circ}$, which are lower than the values previously observed [16]. This may be attributed to the steric repulsion generated by the 5phenyl substitution. On a related observation, the torsions of the 5-phenyl ring relative to the 2-iminopyrrolyl moiety are in the range of $31.35-31.98^{\circ}$.

The coordination geometry of complex $\mathbf{2 b}$ is very similar to those of complexes $1 \mathbf{a}-\mathbf{2 a}$, with the $\mathrm{Co}-\mathrm{N}$ bond lengths and the $\mathrm{N}-\mathrm{Co}-\mathrm{N}$ bond angles falling in the same range, giving rise to a similar $\tau_{4}$ parameter (0.76). Also, the angle between the planes defined by $\mathrm{N} 1-\mathrm{Co} 1-\mathrm{N} 2$ and N3-Co1-N4 is $84.68^{\circ}$, which is comparable to those of complexes 1a-2a. The torsions of the 2,6-diisopropylphenyl ring bonded to the iminic nitrogen and of the 5(2,6-dimethylphenyl) ring relative to the 2-iminopyrrolyl moiety are in the range of $75.39-79.36^{\circ}$ and $77.27-82.08^{\circ}$, respectively. Furthermore, the five-membered chelates (defined by the atoms Co1-N1-C2-C6-N2 and Co1-N3-C25-C29-N4) are significantly deviated from planarity $\left(19.2-22.7^{\circ}\right)$, with a clear pyramidalization of the pyrrolyl nitrogen atoms, as opposed to the near planar chelates in complexes 1a-2a. These last observations for complex $\mathbf{2 b}$ are attributed to the extra stereochemical stress imparted by the 2,6dimethylphenyl substituents.

Complex $\mathbf{1 b}$ is also tetracoordinated, the ligands exhibiting the typical bidentate coordination mode. The $\mathrm{Fe}-\mathrm{N}$ bond lengths are in the expected range and the chelate bite angles are also very similar to those of complexes $\mathbf{1 a}, \mathbf{2 a}$ and $\mathbf{2 b}$. Contrasting with these similarities, the main difference stands in the $\mathrm{N}-\mathrm{Fe}-\mathrm{N}$ bond angles between the two ligands, giving rise to a $\tau_{4}$ parameter of 0.55 , an intermediate case between tetrahedral and square 
planar [21]. The angle between the planes defined by $\mathrm{N} 1-\mathrm{Fe} 1-\mathrm{N} 2$ and $\mathrm{N} 3-\mathrm{Fe} 1-\mathrm{N} 4$ is $63.37(7)^{\circ}$, being much more deviated from orthogonality than in the remaining complexes. As in complex $\mathbf{2 b}$, albeit not as pronounced, the five-membered chelation rings in complex $\mathbf{1 b}$ are also modestly deviated from planarity $\left(10.2-16.0^{\circ}\right)$, with the pyrrolyl nitrogen atom in a slight pyramidal conformation. The marked differences between complexes $\mathbf{1 b}$ and $\mathbf{2 b}$ are explained by the additional steric bulkiness of the 2,6-dimethylphenyl groups: (a) planar chelation rings of the respective ligands in complex $\mathbf{1 b}$ but a very distorted coordination geometry; (b) pyramidalized pyrrolyl nitrogen atoms in complex $\mathbf{2 b}$, but a less distorted coordination geometry.

The resulting highly distorted geometry of complex $\mathbf{1 b}$ can be better described as: (a) a seesaw-like geometry, in which the quite linear N1-Fe1-N3 $\left(155.74(7)^{\circ}\right)$ forms the plank and the N2-Fe1-N4 (126.43(7) $)^{\circ}$ forms the pivot, similar to that observed by Bochmann et al. in the only crystalographically characterized Fe(II) compound supported by the bis(2iminopyrrolyl) scaffold [6]; or (b) a severely distorted trigonal pyramidal geometry $\left(\tau_{4}=0.85\right.$ in the pure undistorted case [21]), in which N1, N3 and N4 form the trigonal plane with the Fe1 atom sitting only $0.309 \AA$ above it and N2 occupying the distorted apical position, with the Fe1-N2 bond forming an angle of $82.51^{\circ}$ with that plane, the best example in the literature of a Fe trigonal pyramidal geometry being that of $\mathrm{Fe}(\mathrm{II})$ complexes supported by tris(pyrrolyl- $\alpha$-methyl)amine tripodal ligands reported by Chang et al. [3] Alternatively, the geometry of $\mathbf{1 b}$ could also be regarded as reminiscent of distorted trigonal bipyramidal, in which $\mathrm{N} 1$ and $\mathrm{N} 3$ are in the apical positions, N2 and N4 occupy two equatorial positions, the remaining third equatorial position being vacant. This vacant position makes complex $\mathbf{1 b}$ more susceptible of additional reactivity (namely towards water and oxygen) since its $\mathrm{Fe}$ atom is more coordinatively exposed than in compounds $\mathbf{1 a}, \mathbf{2 a}$ and $\mathbf{2} \mathbf{b}$, as shown in their spacefill views (Fig. S5 of the Supplementary data).

\subsection{Magnetic susceptibility measurements in the solid state}

In order to confirm the electronic states of the complexes and understand how these geometrical distortions could affect the magnetic properties of these complexes, measurements in the solid state of the four complexes of Fe (1a and 1b) and Co (2a and $\mathbf{2 b}$ ) were carried out. The magnetic susceptibility was thus measured as a function of temperature in the range of 5-300 K. The plots of the $\chi_{M} T v s . T$ measured at 500 Oe are shown in Fig. 2 
( $\chi_{M}$ is the molar magnetic susceptibility per formula unit). These measurements revealed a paramagnetic character for these complexes. At room temperature, the $\chi_{M} T$ product of the $\mathrm{Fe}$ complexes 1a and $\mathbf{1 b}$ was found to be 3.94 and $3.91 \mathrm{~cm}^{3} \mathrm{~mol}^{-1} \mathrm{~K}$, respectively. These values are higher than the spin-only value expected for tetrahedral $\mathrm{Fe}$ (II) complexes with an isotropic ${ }^{5} \mathrm{~A}_{1}$ electronic ground state $\left(\chi_{M} T=3.0 \mathrm{~cm}^{3} \mathrm{~mol}^{-1} \mathrm{~K}\right.$ for $S=2$ and $\left.g=2\right)$. They result from an efficient mixing of the ground state with (orbitally unquenched) excited states, as it was previously observed in other tetrahedral Fe(II) complexes [20,22]. These results are coherent with the magnetic susceptibility measurements performed in solution using the Evans method mentioned above (see also Table 2, $\mu_{\text {eff }}=2.84\left(\chi_{M} T\right)^{1 / 2}$ ) and the electronic configuration agree with the ${ }^{57} \mathrm{Fe}$ Mössbauer data referred below.

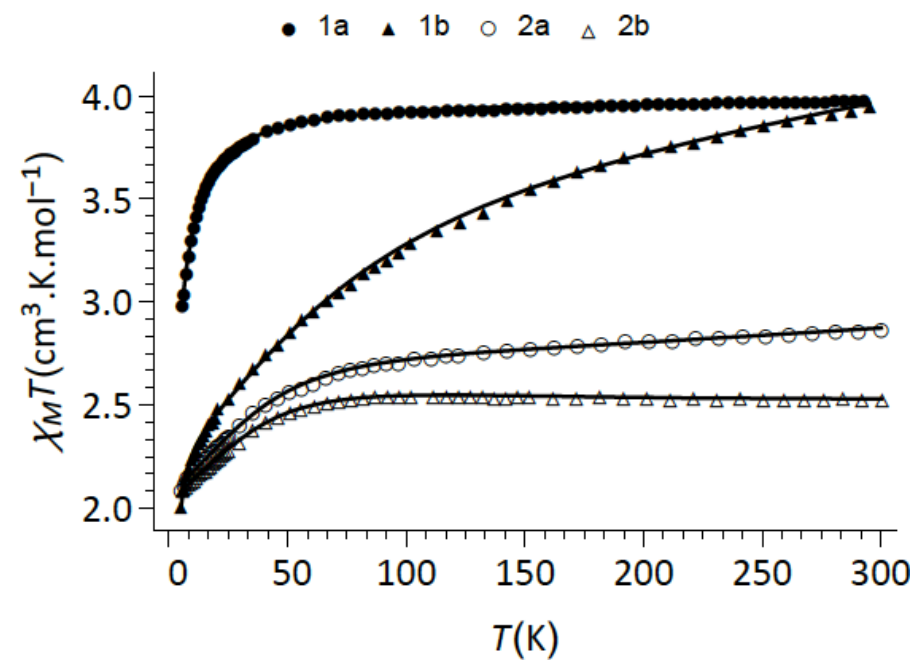

Fig. 2 Temperature dependence of the product of molar magnetic susceptibility with temperature, $\chi_{M} T$, with a magnetic field of $500 \mathrm{Oe}$ for $\mathrm{Fe}(\mathbf{1 a}, \mathbf{1 b}$; full symbols) and Co (2a, $\mathbf{2} \mathbf{b}$; open symbols) complexes. The lines represent the best simulation (see text).

Table 2 Effective magnetic moments $\mu_{\text {eff }}\left(\mu_{\mathrm{B}}\right)$ for the Fe(II) (1a, 1b) and Co(II) (2a, 2b) complexes, measured in toluene- $d_{8}$ solution (Evans method) and in the solid state (SQUID method), at r.t.

\begin{tabular}{cccc}
\hline Complex & Evans & & SQUID \\
\cline { 2 - 2 } & $\mu_{\text {eff }}\left(\mu_{\mathrm{B}}\right)$ & & $\mu_{\text {eff }}\left(\mu_{\mathrm{B}}\right)$ \\
\hline 1a & 5.9 & 5.64 \\
1b & 5.6 & & 5.62 \\
$\mathbf{2 a}$ & 4.8 & & 4.79 \\
$\mathbf{2 b}$ & 5.0 & & 4.50 \\
\hline
\end{tabular}

Although presenting a similar value at room temperature (r.t.), the $\chi_{M} T v s T$ curves of the complexes $\mathbf{1 a}$ and $\mathbf{1 b}$ behave differently. With the decrease of temperature, complex $\mathbf{1 a}$ is 
almost temperature independent down to $35 \mathrm{~K}$. Below $35 \mathrm{~K}$ it decreases until reaching the value of $2.95 \mathrm{~cm}^{3} \mathrm{~mol}^{-1} \mathrm{~K}$, at $5 \mathrm{~K}$. For complex $\mathbf{1 b}$, from room temperature down to $5 \mathrm{~K}$, a continuous decrease of the $\chi_{M} T$ product is observed, reaching at $5 \mathrm{~K}$ the value $1.98 \mathrm{~cm}^{3} \mathrm{~mol}^{-1}$ $\mathrm{K}$, lower than that of 1a. Since the interatomic distances between $\mathrm{Fe}-\mathrm{Fe}$ atoms are very large in both cases (> $10 \AA$ ), the non-Curie behaviour cannot be ascribed to intermolecular magnetic interactions. They are rather due to the magnetic anisotropy of the complexes, which can result from the second order spin-orbit coupling and some geometrical distortion in the coordination sphere [23]. A larger distortion in $\mathbf{1 b}$ could lead to a stronger anisotropy. In order to quantify this effect, the magnetic properties were simulated with the PHI program [24] and by using the following Hamiltonian:

$\widehat{H}=D \hat{S}_{z}^{2}+E\left(\hat{S}_{y}-\hat{S}_{x}\right)+g \mu_{B} \boldsymbol{S H}$

The first term is the zero-field splitting (ZFS), an effective spin Hamiltonian, which accounts for the magnetic anisotropy. $D$ and $E$ are the axial and rhombic anisotropy terms, respectively. $\mu_{B}$ is the Bohr magneton and $g$ is the Landé factor. In our simulations, we had to consider an axial $g$ tensor to obtain satisfactory results. The best fit for 1a was obtained for: $D$ $=4.8 \mathrm{~cm}^{-1}$ and $g_{1}=g_{2}=2.12, g_{3}=2.63$. These values are coherent with those found in previously reported tetrahedral Fe(II) complexes [22]. The simulation of $\mathbf{1 b}$ led to a strongly negative $\mathrm{D}$ value and it was necessary to take into account the transverse anisotropy, $E$ The best fit was obtained with the following set of parameters: $D=-53.8 \mathrm{~cm}^{-1}, E=9.2 \mathrm{~cm}^{-1}, g_{l}=$ $g_{2}=2.18, g_{3}=2.13$ (positive values of $D$ lead to unreasonable values of $g$ ). The higher anisotropy observed in $\mathbf{1 b}$ is very likely due to the peculiar distortion of its coordination sphere. Most of the $\mathrm{Fe}(\mathrm{II})$ tetrahedral complexes previously reported exhibit a similar behaviour as 1a, however it is worth noticing that such large $\mathrm{D}$ values have been predicted by E. Ruiz et al. in distorted tetrahedral complexes [25].

The $\chi_{M} T$ values measured at room temperature for the Co complexes $\mathbf{2 a}$ and $\mathbf{2 b}$ are 2.84 and $2.51 \mathrm{~cm}^{3} \mathrm{~mol}^{-1} \mathrm{~K}$ (Fig. 2), respectively. They agree well with the magnetic moments determined by the Evans method (Table 2) suggesting that the structures of the complexes are similar in solution and in the solid state. The experimental values are significantly above the calculated spin-only value for high-spin $\mathrm{Co}(\mathrm{II}), 1.86 \mathrm{~cm}^{3} \mathrm{~mol}^{-1} \mathrm{~K}(S=3 / 2$ and $g=2)$, but well within the range of the observed experimental values for Co(II) compounds $[16,19,20]$. Upon cooling, the $\chi_{M} T$ values remain almost constant down to $c a .100 \mathrm{~K}$ and then decrease 
continuously reaching the value of $2.07 \mathrm{~cm}^{3} \mathrm{~mol}^{-1} \mathrm{~K}$ at $5 \mathrm{~K}$. As for the Fe complexes, the long distances between the complexes in the crystal lattice allow discarding the influence of intermolecular exchange interactions. This behaviour is thus ascribed to the effect of the second order spin-orbit coupling that leads to a magnetic anisotropy. The magnetic data were thus simulated following the same procedure as the one described above. The best simulations were obtained for the following set of parameters: $D=-53.0 \mathrm{~cm}^{-1}, g_{1}=g_{2}=2.10$, $g_{3}=2.70$, for $\mathbf{2 a}$, and $D=-51.3 \mathrm{~cm}^{-1}, g_{1}=g_{2}=2.01, g_{3}=2.69$, for $\mathbf{2 b}$. The values obtained for these parameters in both complexes are very close, which is coherent with the structural similarities between them. They are also similar to those obtained in the literature for similar tetracoordinated $\mathrm{Co}(\mathrm{II})$ complexes.[2,26].

\subsection{Mössbauer spectroscopy}

The Mössbauer spectra of 1a (Fig. 4) show a single quadrupole doublet with estimated isomer shift relative to metallic $\alpha \mathrm{Fe}$ at $295 \mathrm{~K}$, IS, and quadrupole splitting, QS (Table S2 of the Supplementary data) consistent with high-spin Fe(II), $S=2$, in a distorted tetrahedral coordination [27]. In the measured temperature range, 295-1.7 $\mathrm{K}$, the samples are paramagnetic and the spectra evidence no magnetic transition.

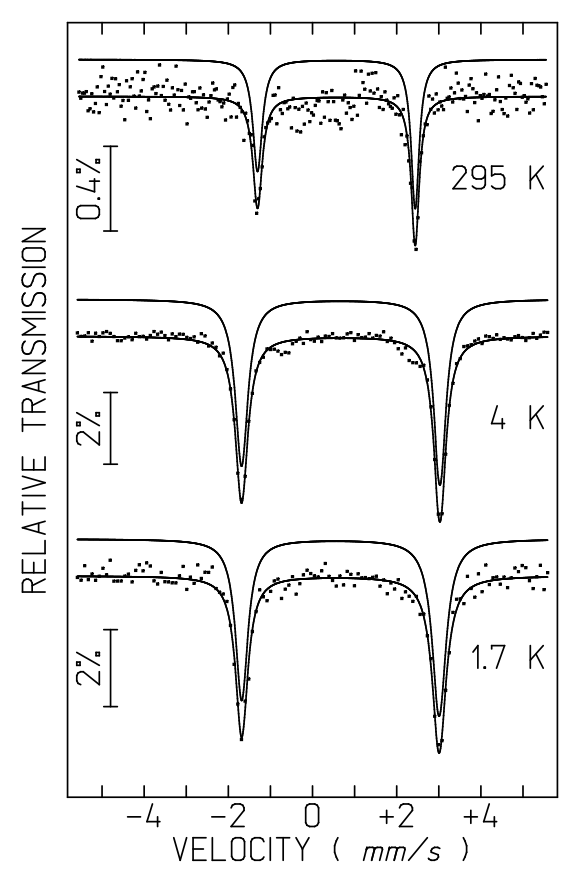

Fig. 3 Mössbauer spectra of complex 1a taken at different temperatures. The line on the experimental points is the calculated doublet due to $\mathrm{Fe}(\mathrm{II})$ in the $S=2$ spin state. 
The spectra of complex 1b (Fig. 5) in the temperature range 70-295 K show, in addition to high-spin Fe(II), a second doublet with lower IS and QS consistent with high-spin Fe(III) [27]. This assignment is confirmed by the $4 \mathrm{~K}$ measurement where the small QS doublet gives rise to a sextet with magnetic hyperfine field (Table S2 of the Supplementary data) typical for high-spin, $S=5 / 2, \mathrm{Fe}(\mathrm{III})$. No magnetic transition is observed for $\mathrm{Fe}(\mathrm{II})$ in the range 4-295 K. The observed increase in the IS values, for both samples $\mathbf{1 a}$ and $\mathbf{1 b}$, as the temperature decreases from $295 \mathrm{~K}$ down to $4 \mathrm{~K}$ is explained by the second order Doppler shift [27]. The presence of Fe(III) in sample $\mathbf{1 b}$ in the Mössbauer absorber is consistent with the fact that this complex is considerably more unstable than 1a, since in both cases the perspex sample holder, which was filled with the sample in a glovebox, is not airtight and was handled in air in its transfer to the spectrometer. At variance, as referred above, the sample 1b used for the SQUID experiments was transferred to a quartz tube in a glovebox and sealed under dinitrogen. Consequently, the sample 1b used for SQUID measurements was not oxidized.

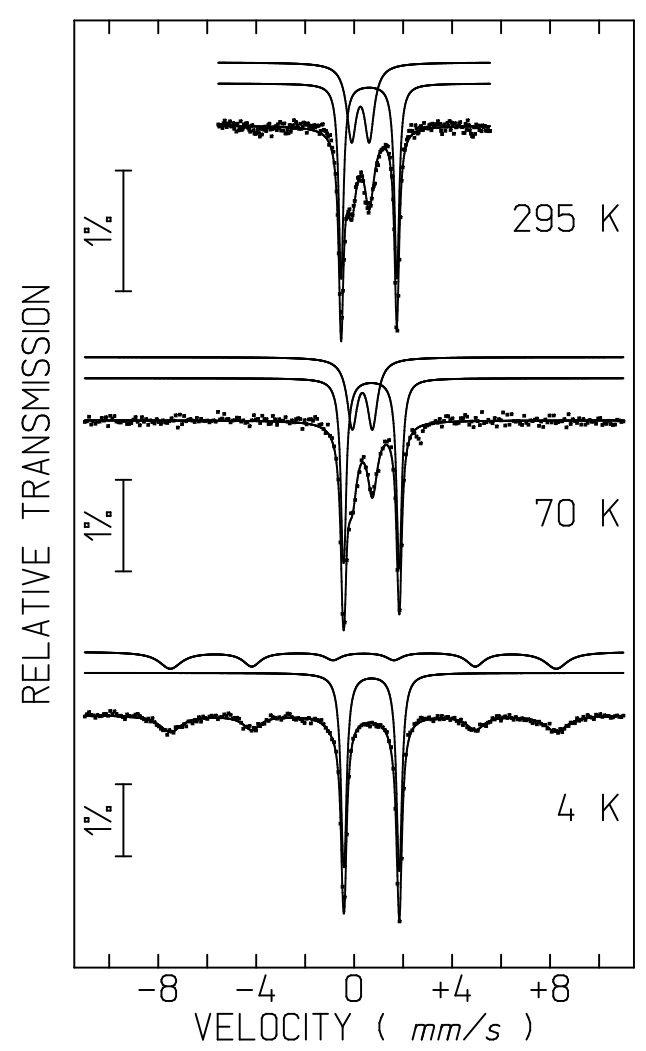

Fig. 4 Mössbauer spectra of complex $1 \mathbf{b}$ taken at different temperatures. The line on the experimental points is the sum of the calculated doublet due to $\mathrm{Fe}$ (II) in the $S=2$ spin state and the doublet ( 295 and $70 \mathrm{~K}$ ) or sextet (4 K) due to $\mathrm{Fe}$ (III) in the $S=5 / 2$ spin state. 
The estimated QS values for Fe(II) in 1a and 1b (Table S2 of the Supplementary data) confirm that the coordination geometry distortion of the $\mathrm{Fe}(\mathrm{II})$ site in $\mathbf{1 b}$ is very high, in particular much stronger than in 1a. High-spin Fe(II) quadrupole splittings depend both on the electric field gradient arising from the lattice charge distribution, $q_{\text {latt }}$, and on due to the $d$ electron distribution [28]. The $d$ electron distribution depends on the crystal field and on the occupation of the ground and first excited states. Parameters $q_{\text {latt }}$ and $q_{e l}$ have opposite signs and the absolute value of $q_{e l}$ is higher than $q_{\text {latt }}$ since the electronic charge distribution is much closer to the Fe nuclei than the charges of the lattice. The total quadrupole splitting is therefore directly related to $q_{e l}-q_{\text {latt }}$. If there are no phase transitions between $4 \mathrm{~K}$ and $295 \mathrm{~K}$, $q_{\text {latt }}$ remains approximately constant in the same temperature range. On the other hand, if there are low-lying excited electronic states, $q_{e l}$ decreases with increasing temperature as observed for 1a. However, if the coordination geometry distortion is huge, the occupation of electronic excited states is negligible in the 4-295 K temperature range and, in this case, QS of high-spin Fe(II) will be temperature independent, as observed for 1b. Furthermore, QS for the more distorted site in $\mathbf{1 b}$ is expected to be lower than in $\mathbf{1 a}$ since $q_{\text {latt }}$ for $\mathbf{1 a}$ is much lower than for $\mathbf{1 b}$ and therefore $q_{e l}-q_{\text {latt }}$ will be higher for the least distorted site.

\section{Conclusions}

A family of highly electronically unsaturated $\mathrm{Fe}(\mathrm{II})$ and $\mathrm{Co}(\mathrm{II})$ bis(5-aryl-2-iminopyrrolyl) complexes of the type $\left[\mathrm{M}\left\{\kappa^{2} N, N-5-\left(2,6-\mathrm{R}_{2}-\mathrm{C}_{6} \mathrm{H}_{3}\right)-\mathrm{NC}_{4} \mathrm{H}_{2}-2-\mathrm{C}(\mathrm{H})=\mathrm{N}\left(2,6-{ }^{\mathrm{i}} \mathrm{Pr}_{2}-\mathrm{C}_{6} \mathrm{H}_{3}\right)\right\}_{2}\right]$, with $\mathrm{M}=\mathrm{Fe}(\mathbf{1})$ or $\mathrm{Co}(\mathbf{2})$ and $\mathrm{R}=\mathrm{H}$ (a) or $\mathrm{Me}(\mathbf{b})$, has been prepared and characterized. The two sterically congested new 5-aryl-2-iminopyrrolyl ligands protect the metal center giving rise to isolable homoleptic four-coordinate complexes with distorted tetrahedral geometries, as indicated by X-ray diffraction studies. Magnetic measurements in solution and in the solid state, as well as ${ }^{57} \mathrm{Fe}$ Mössbauer spectroscopy demonstrated high-spin states for all four complexes.

The distortion of the Fe(II) site on $\mathbf{1 b}$ is particularly strong as evidenced not only by the X-ray diffraction studies but also by the temperature independent value of the $\mathrm{Fe}(\mathrm{II})$ quadrupole splitting in Mössbauer data. This strong distortion leads to a more coordinatively exposition of the Fe atoms than in compounds $\mathbf{1 a}, \mathbf{2 a}$ and $\mathbf{2 b}$, and consequently to a higher sensitivity to air and moisture of $\mathbf{1 b}$. The solid-state magnetic study is coherent with the structural data and the simulation of the $\chi_{M} T$ vs $T$ curve of $\mathbf{1 b}$ revealed a high magnetic 
anisotropy with both axial and rhombic ZFS contributions, which is quite uncommon for tetracoordinated $\mathrm{Fe}(\mathrm{II})$ complexes.

\section{Experimental}

\subsection{General}

All operations were performed under dry dinitrogen atmosphere using standard glovebox and Schlenk techniques. Solvents were pre-dried with molecular sieves and distilled by refluxing under dinitrogen for several hours over suitable drying agents (sodium/benzophenone for THF; $\mathrm{CaH}_{2}$ for $n$-hexane). Solvents and solutions were transferred using a positive pressure of nitrogen through stainless steel cannulae and mixtures were filtered in a similar way using modified cannulae that could be fitted with glass fiber filter disks.

The compounds 5-phenyl-2-formyl-1H-pyrrole and 5-(2,6-dimethylphenyl)-2-formyl-1Hpyrrole were prepared as reported in the literature [18].

Elemental analyses were obtained from the IST elemental analysis services.

\subsection{Synthesis of the ligand precursors}

\subsubsection{5-phenyl-2-(N-2,6-diisopropylphenylformimino)pyrrole (Ia)}

5-phenyl-2-formyl-1H-pyrrole (0.748 g; $4.4 \mathrm{mmol})$, 2,6-diisopropylaniline $(0.80 \mathrm{ml} ; 4.2$ $\mathrm{mmol})$ and a catalytic amount of $p$-toluenesulfonic acid $(0.040 \mathrm{~g} ; 0.21 \mathrm{mmol})$ were suspended in toluene $(20 \mathrm{ml})$ in a round-bottom flask and the mixture refluxed at $140{ }^{\circ} \mathrm{C}$ for 60 hours. After cooling to room temperature the solvent was removed under vacuum. Extraction with $n$-hexane gave a brown-orange solution, in which the product and aniline reagent coprecipitated together. The $n$-hexane was evaporated and the residue dried in high vacuum, at $120^{\circ} \mathrm{C}$, in order to evaporate the excess of reagent. The remaining oily paste was re-dissolved in $n$-hexane and stored at $-20{ }^{\circ} \mathrm{C}$. The brown solid precipitate of Ia was filtered and dried under vacuum. Yield: $1.23 \mathrm{~g}(86 \%)$.

Anal. Calc. for $\mathrm{C}_{23} \mathrm{H}_{26} \mathrm{~N}_{2} \cdot 0.25\left(-\mathrm{Si}\left(\mathrm{CH}_{3}\right)_{2} \mathrm{O}-\right)$ : C, 80.87; H, 7.94; N, 8.03. Found: C, 80.23; $\mathrm{H}, 8.04 ; \mathrm{N}, 8.13 .{ }^{1} \mathrm{H}$ NMR $\left(300 \mathrm{MHz}, \mathrm{CDCl}_{3}\right): \delta \mathrm{N} H$ resonance absent, $7.93(\mathrm{~s}, 1 \mathrm{H}, \mathrm{CH}=\mathrm{N})$, $7.65\left(\mathrm{~d},{ }^{3} J_{\mathrm{HH}}=7.5 \mathrm{~Hz}, 2 \mathrm{H}, 5-\mathrm{Ph}-\mathrm{H}_{\text {ortho }}\right), 7.43\left(\mathrm{t},{ }^{3} J_{\mathrm{HH}}=7.6 \mathrm{~Hz}, 2 \mathrm{H}, 5-\mathrm{Ph}-\mathrm{H}_{\text {meta }}\right), 7.31\left(\mathrm{t},{ }^{3} J_{\mathrm{HH}}=\right.$ $\left.7.3 \mathrm{~Hz}, 1 \mathrm{H}, 5-\mathrm{Ph}-\mathrm{H}_{\text {para }}\right), 7.19-7.12\left(\mathrm{~m}, 3 \mathrm{H}, \mathrm{N}-\mathrm{Ph}-\mathrm{H}_{\text {meta }}\right.$ and $\left.\mathrm{N}-\mathrm{Ph}-\mathrm{H}_{\text {para }}\right), 6.69\left(\mathrm{~d},{ }^{3} J_{\mathrm{HH}}=3.6\right.$ 
$\mathrm{Hz}, 1 \mathrm{H}, \mathrm{H}_{3}$ pyrr $), 6.64\left(\mathrm{~d},{ }^{3} J_{\mathrm{HH}}=3.7 \mathrm{~Hz}, 1 \mathrm{H}, \mathrm{H}_{4}\right.$ pyrr $), 3.13-2.99\left(\mathrm{~m}, 2 \mathrm{H}, \mathrm{CH}\left(\mathrm{CH}_{3}\right)_{2}\right), 1.18(\mathrm{~d}$, $\left.{ }^{3} J_{\mathrm{HH}}=6.9 \mathrm{~Hz}, 12 \mathrm{H}, \mathrm{CH}\left(\mathrm{CH}_{3}\right)_{2}\right) .{ }^{13} \mathrm{C}\left\{{ }^{1} \mathrm{H}\right\} \mathrm{NMR}\left(75 \mathrm{MHz}, \mathrm{CDCl}_{3}\right): \delta 151.8(\mathrm{CH}=\mathrm{N}), 148.7$ $\left(\mathrm{N}-\mathrm{Ph}-\mathrm{C}_{\text {ipso }}\right), 138.5$ (N-Ph-C $\left.\mathrm{C}_{\text {ortho }}\right), 136.7$ ( $\mathrm{C}_{5}$ pyrr), 131.5 (5-Ph- $\left.\mathrm{C}_{i p s o}\right), 130.9\left(\mathrm{C}_{2}\right.$ pyrr $), 129.0$ (5-Ph-C $\left.\mathrm{C}_{\text {meta }}\right), 127.6$ (5-Ph-C $\left.\mathrm{C}_{\text {para }}\right), 124.7$ (5-Ph-C $\left.\mathrm{C}_{\text {ortho }}\right), 124.1\left(\mathrm{~N}-\mathrm{Ph}-\mathrm{C}_{\text {para }}\right), 123.1\left(\mathrm{~N}-\mathrm{Ph}-\mathrm{C}_{\text {meta }}\right)$, 117.6 ( $\mathrm{C}_{3}$ pyrr $), 107.9\left(\mathrm{C}_{4}\right.$ pyrr $), 27.9\left(\mathrm{CH}\left(\mathrm{CH}_{3}\right)_{2}\right), 23.7\left(\mathrm{CH}\left(\mathrm{CH}_{3}\right)_{2}\right)$.

\subsubsection{5-(2,6-dimethylphenyl)-2-(N-2,6-diisopropylphenylformimino)pyrrole (Ib)}

5-(2,6-dimethylphenyl)-2-formyl-1H-pyrrole ${ }^{18}$ (0.636 g; $\left.3.2 \mathrm{mmol}\right)$, 2,6-diisopropylaniline $(0.71 \mathrm{~mL} ; 3.8 \mathrm{mmol})$ and a catalytic amount of $p$-toluenesulfonic acid (30 mg; $0.16 \mathrm{mmol})$ were suspended in toluene $(20 \mathrm{ml})$ in a round-bottom flask and the mixture refluxed at $140{ }^{\circ} \mathrm{C}$ for 48 hours. After cooling to room temperature the solvent was removed under vacuum. Purification was carried out by column chromatography with $n$-hexane:ethyl acetate $(4: 1)$ as eluent. The combined fractions were evaporated, yielding Ib as a dark orange solid. Yield: $0.870 \mathrm{~g}(76 \%)$.

Anal. Calc. for $\mathrm{C}_{25} \mathrm{H}_{30} \mathrm{~N}_{2} \cdot 0.065\left(-\mathrm{Si}\left(\mathrm{CH}_{3}\right)_{2} \mathrm{O}-\right)$ : C, 83.06; H, 8.44; N, 7.71. Found: C, 82.92; $\mathrm{H}, 8.80 ; \mathrm{N}, 7.74 .{ }^{1} \mathrm{H} \mathrm{NMR}\left(300 \mathrm{MHz}, \mathrm{CDCl}_{3}\right): \delta 9.15$ (br, $\left.1 \mathrm{H}, \mathrm{NH}\right), 7.96(\mathrm{~s}, 1 \mathrm{H}, \mathrm{CH}=\mathrm{N})$, 7.24-7.21 (m, 1H, 5-Ph- $\mathrm{H}_{\text {para }}$ ), 7.18-7.09 (m, 5H, 5-Ph- $\mathrm{H}_{\text {meta }}, \mathrm{N}-\mathrm{Ph}-\mathrm{H}_{\text {meta }}$ and $\mathrm{N}-\mathrm{Ph}-\mathrm{H}_{\text {para }}$ ), $6.71\left(\mathrm{~d},{ }^{3} \mathrm{~J}_{\mathrm{HH}}=3.3 \mathrm{~Hz}, 1 \mathrm{H}, \mathrm{H}_{3}\right.$ pyrr $), 6.23\left(\mathrm{~d},{ }^{3} J_{\mathrm{HH}}=3.3 \mathrm{~Hz}, 1 \mathrm{H}, \mathrm{H}_{4}\right.$ pyrr $), 3.14-3.00(\mathrm{~m}, 2 \mathrm{H}$, $\left.\mathrm{CH}\left(\mathrm{CH}_{3}\right)_{2}\right), 2.28\left(\mathrm{~s}, 6 \mathrm{H}, \mathrm{CH}_{3}\right), 1.20\left(\mathrm{~d},{ }^{3} \mathrm{~J}_{\mathrm{HH}}=6.9 \mathrm{~Hz}, 12 \mathrm{H}, \mathrm{CH}\left(\mathrm{CH}_{3}\right)_{2}\right) .{ }^{13} \mathrm{C}\left\{{ }^{1} \mathrm{H}\right\} \mathrm{NMR}(75$ $\left.\mathrm{MHz}, \mathrm{CDCl}_{3}\right): \delta 151.5(\mathrm{CH}=\mathrm{N}), 149.2\left(\mathrm{~N}-\mathrm{Ph}-\mathrm{C}_{i p s o}\right), 138.4\left(\mathrm{~N}-\mathrm{Ph}-\mathrm{C}_{\text {ortho }}\right), 138.3\left(5-\mathrm{Ph}-\mathrm{C}_{\text {ortho }}\right)$, 134.7 ( $\mathrm{C}_{5}$ pyrr), 132.6 (5-Ph- $\left.\mathrm{C}_{\text {ipso }}\right), 130.3$ ( $\mathrm{C}_{2}$ pyrr), 128.6 (5-Ph- $\left.\mathrm{C}_{\text {para }}\right), 127.7$ (5-Ph- $\left.\mathrm{C}_{\text {meta }}\right)$, $124.0\left(\mathrm{~N}-\mathrm{Ph}-\mathrm{C}_{\text {para }}\right), 123.2\left(\mathrm{~N}-\mathrm{Ph}-\mathrm{C}_{\text {meta }}\right), 116.0\left(\mathrm{C}_{3}\right.$ pyrr $), 110.8\left(\mathrm{C}_{4}\right.$ pyrr $), 28.1\left(\mathrm{CH}\left(\mathrm{CH}_{3}\right)_{2}\right)$, $23.7\left(\mathrm{CH}\left(\mathrm{CH}_{3}\right)_{2}\right), 20.9\left(\mathrm{CH}_{3}\right)$.

\subsection{Synthesis of the complexes}

4.3.1. General method for the synthesis of $\left[M\left\{\kappa^{2} N, N-5-\left(2,6-R_{2}-C_{6} H_{3}\right)-N C_{4} H_{2}-2-\right.\right.$ $\left.\left.C(H)=N\left(2,6-{ }^{i} \mathrm{Pr}_{2}-\mathrm{C}_{6} \mathrm{H}_{3}\right)\right\}_{2}\right](M=\mathrm{Fe}(\mathbf{1})$ or $\mathrm{Co}(2)$ and $R=H(\boldsymbol{a})$ or $M e(\boldsymbol{b}))$

$\mathrm{NaH}$ (2.2 equivalents) was suspended in THF and $\mathbf{I a}(\mathrm{R}=\mathrm{H})$ or $\mathbf{I b}(\mathrm{R}=\mathrm{Me})$ (2 equivalents) was added as a solid, under a counter flow of dinitrogen, yielding a pale red suspension. The mixture was stirred for $3 \mathrm{~h}$ at $80{ }^{\circ} \mathrm{C}$ under dinitrogen, yielding brown (for $\mathrm{R}=\mathrm{H}$ ) or pale orange (for $\mathrm{R}=\mathrm{Me}$ ) suspensions. The suspension was allowed to settle as it cooled to room temperature. This solution was filtered and added dropwise to a THF suspension of 
anhydrous $\mathrm{MCl}_{2}\left(\mathrm{M}=\mathrm{Fe}\right.$ or $\mathrm{Co} ; 1$ equivalent), which was cooled to $-78^{\circ} \mathrm{C}$. The mixture was allowed to warm up to room temperature while stirring overnight. All volatile materials were evaporated under reduced pressure and the residue dried under vacuum. The solid was extracted with $n$-hexane until extracts were colorless. The extracts were combined and the resulting solution was concentrated and stored at $-20^{\circ} \mathrm{C}$. After a few days, the title compounds were obtained as crystalline solids suitable for X-ray diffraction.

\subsubsection{1. [Fe $\left.\left\{\kappa^{2} N, N^{\prime}-5-\left(C_{6} H_{5}\right)-N C_{4} H_{2}-2-C(H)=N\left(2,6-{ }^{i} \mathrm{Pr}_{2}-C_{6} H_{3}\right)\right\}_{2}\right]($ la $)$}

This complex was prepared as described above, using $\mathrm{FeCl}_{2}(0.064 \mathrm{~g}, 0.5 \mathrm{mmol})$, the ligand precursor Ia $(0.33 \mathrm{~g}, 1 \mathrm{mmol})$ and $\mathrm{NaH}(0.026 \mathrm{~g}, 1.1 \mathrm{mmol})$ and obtained as a red crystalline solid. Yield: $0.14 \mathrm{~g}(39 \%)$.

Anal. Calc. for $\mathrm{C}_{46} \mathrm{H}_{50} \mathrm{FeN}_{4}$ : C, 77.30; H, 7.05; N, 7.84. Found: C, 76.31; H, 7.36; N, 7.76. $\mu_{\text {eff }}\left(\right.$ toluene- $\left.d_{8}\right)=5.9 \mu_{\mathrm{b}} .{ }^{1} \mathrm{H}$ NMR $\left(300 \mathrm{MHz}, \mathrm{C}_{6} \mathrm{D}_{6}\right): \delta 59.6,54.9$ (br) 24.0 (br), 20.1, 13.8, 9.6, 9.2 (br), 5.2 (br), 1.2, 0.9 (br), -1.0, -3.9 (br), -9.2, -27.2.

\subsubsection{2. $\left[\mathrm{Fe}\left\{\kappa^{2} \mathrm{~N}, N^{\prime}-5-\left(2,6-\mathrm{Me}_{2}-\mathrm{C}_{6} \mathrm{H}_{3}\right)-\mathrm{NC}_{4} \mathrm{H}_{2}-2-\mathrm{C}(\mathrm{H})=\mathrm{N}\left(2,6-{ }^{i} \mathrm{Pr}_{2}-\mathrm{C}_{6} \mathrm{H}_{3}\right)\right\}_{2}\right](\mathbf{l b})$}

This complex was prepared as described above, using $\mathrm{FeCl}_{2}(0.064 \mathrm{~g}, 0.5 \mathrm{mmol})$, the ligand precursor Ib $(0.36 \mathrm{~g}, 1 \mathrm{mmol})$ and $\mathrm{NaH}(0.026 \mathrm{~g}, 1.1 \mathrm{mmol})$ and obtained as a red crystalline solid. Yield: $0.20 \mathrm{~g}(52 \%)$.

Anal. Calc. for $\mathrm{C}_{50} \mathrm{H}_{58} \mathrm{FeN}_{4}$ : C, 77.59; H, 7.58; N, 7.27. Found: C, 76.88; H, 7.67; N, 7.21. $\mu_{\text {eff }}\left(\right.$ toluene- $\left.d_{8}\right)=5.6 \mu_{\mathrm{b}} .{ }^{1} \mathrm{H}$ NMR (300 MHz, toluene- $\left.d_{8}\right): \delta$ 67.6, 40.5 (br), 31.9, 21.6 (br), $18.5,16.4,10.1$ (br), 7.4, 6.3, 1.9 (br), 0.9 (br), -2.8, -10.9 (br), -30.4 (br).

\subsubsection{3. [Co $\left.\left\{\kappa^{2} N, N^{\prime}-5-\left(C_{6} H_{5}\right)-N C_{4} H_{2}-2-C(H)=N\left(2,6-{ }^{i} \mathrm{Pr}_{2}-C_{6} H_{3}\right)\right\}_{2}\right](2 a)$}

This complex was prepared as described above, using $\mathrm{CoCl}_{2}(0.097 \mathrm{~g}, 0.75 \mathrm{mmol})$, the ligand precursor Ia $(0.49 \mathrm{~g}, 1.5 \mathrm{mmol})$ and $\mathrm{NaH}(0.038 \mathrm{~g}, 1.6 \mathrm{mmol})$ and obtained as a dark redgreen crystalline solid. Yield: $0.350 \mathrm{~g}(67 \%)$.

Anal. Calc. for $\mathrm{C}_{46} \mathrm{H}_{50} \mathrm{CoN}_{4}$ : C, 76.96; H, 7.02; N, 7.80. Found: C, 76.59; H, 7.40; N, 7.84. $\mu_{\text {eff }}\left(\right.$ toluene- $\left.d_{8}\right)=4.8 \mu_{\mathrm{b}} .{ }^{1} \mathrm{H}$ NMR $\left(300 \mathrm{MHz}, \mathrm{C}_{6} \mathrm{D}_{6}\right): \delta 39.6$ (br), 19.0 (br), 7.7 (br), 0.4 (br), $-12.6,-17.0,-22.5$ (br), -24.4 (br), -.27.2. 


\subsubsection{4. $\left[\mathrm{Co}\left\{\kappa^{2} N, N^{\prime}-5-\left(2,6-\mathrm{Me}_{2}-\mathrm{C}_{6} \mathrm{H}_{3}\right)-\mathrm{NC}_{4} \mathrm{H}_{2}-2-\mathrm{C}(\mathrm{H})=\mathrm{N}\left(2, \mathrm{C}^{\mathrm{i}} \mathrm{Pr}_{2}-\mathrm{C}_{6} \mathrm{H}_{3}\right)\right\}_{2}\right](\mathbf{2 b})$}

This complex was prepared as described above, using $\mathrm{CoCl}_{2}(0.065 \mathrm{~g}, 0.5 \mathrm{mmol})$, the ligand precursor Ib $(0.36 \mathrm{~g}, 1 \mathrm{mmol})$ and $\mathrm{NaH}(0.026 \mathrm{~g}, 1.1 \mathrm{mmol})$ and obtained as a dark red crystalline solid. Yield: $0.24 \mathrm{~g}(61 \%)$.

Anal. Calc. for $\mathrm{C}_{50} \mathrm{H}_{58} \mathrm{CoN}_{4}$ : C, 77.59; H, 7.55; N, 7.24. Found: C, 77.22; H, 7.66; N, 7.26. $\mu_{\text {eff }}\left(\right.$ toluene- $\left.d_{8}\right)=5.0 \mu_{\mathrm{b}} \cdot{ }^{1} \mathrm{H}$ NMR $\left(300 \mathrm{MHz}, \mathrm{C}_{6} \mathrm{D}_{6}\right): \delta 112.1$ (br), 101.7, 83.0 (br), 56.9, 37.9 (br), 28.4 (br), 16.1 (br), 14.5, 6.6, -2.0 (br), -3.0, -4.4, -6.4, -7.6, -8.4 (br), -8.9, -10.5, -12.6 (br), -14.2 (br), -19.3, -21.6 (br), -23.3, -25.2, -26.5 (br), -33.9 (br), -48.9 (br), -52.1 (br).

\subsection{NMR measurements}

The NMR spectra of the ligand precursors and complexes were recorded on a Bruker “AVANCE III" $300 \mathrm{MHz}$ spectrometer at 299.995 MHz $\left({ }^{1} \mathrm{H}\right)$ and $75.4296 \mathrm{MHz}\left({ }^{13} \mathrm{C}\right)$ and referenced to the residual protio-resonances of the corresponding solvents $\left({ }^{1} \mathrm{H}\right)$ and to the carbon resonances of the solvents $\left({ }^{13} \mathrm{C}\right)$. The samples were prepared in a glovebox in normal (ligand precursors) and J. Young (complexes) NMR tubes. Deuterated solvents were dried over activated $4 \AA$ molecular sieves and degassed by the freeze-pump-thaw technique.

The solution magnetic susceptibility measurements of compounds $\mathbf{1 a , b}$ and $\mathbf{2 a , b}$ were carried out by the Evans method [29], using a 3\% solution of hexamethyldisiloxane (internal reference) in toluene- $d_{8}$. These solutions were prepared in a glovebox in J. Young NMR tubes containing capillary tubes filled with the same solvent mixture, in which the hexamethyldisiloxane is the external reference.

\subsection{X-ray diffraction}

Crystallographic and experimental details of crystal structure determinations are listed in Table S1 of the Supporting Information. The crystals were selected under an inert atmosphere, covered with dry and degassed polyfluoroether oil and mounted on a nylon loop. Crystallographic data were collected using graphite monochromated Mo-K $\alpha$ radiation $(\lambda=$ $0.71073 \AA$ ) on a Bruker AXS-KAPPA APEX II diffractometer equipped with an Oxford Cryosystem open-flow nitrogen cryostat, at $150 \mathrm{~K}$. Cell parameters were retrieved using Bruker SMART software [30] and refined using Bruker SAINT [31] on all observed reflections. Absorption corrections were applied using SADABS [32]. Structure solution and refinement were performed using direct methods with the programs SIR2014 [33] included in the package of programs WINGX-Version 2014.1 [34]. All hydrogen atoms were inserted in 
idealized positions and allowed to refine riding on the parent carbon atom. All the structures refined to a perfect convergence. Graphic presentations were prepared with ORTEP-3 [35]. Data was deposited in CCDC under the deposit numbers 1815703 for $\mathbf{1 a}, 1815704$ for $\mathbf{1 b}$, 1815705 for $\mathbf{2 a}$ and 1815706 for $\mathbf{2 b}$.

\subsection{Solid state magnetic measurements}

Magnetic properties were studied using a $6.5 \mathrm{~T}$ S700X SQUID (Cryogenic Ltd.) magnetometer. All the four samples were transferred to the sample holder in a glovebox. Due to its high air sensitivity, the sample 1b was transferred to a quartz tube inside a glovebox, which was then sealed under dinitrogen. For all samples, the magnetic susceptibility was measured as a function of temperature in increasing temperature range 5-300 K using DC magnetic fields of 100 Oe or 500 Oe depending on the samples. The paramagnetic data was obtained after the correction for the core diamagnetism estimated using Pascal's constants, giving $\chi_{D}=-542 \times 10^{-6}, \chi_{D}=-589 \times 10^{-6}, \chi_{D}=-541 \times 10^{-6}$, and $\chi_{D}=-587 \times 10^{-6} \mathrm{emu} \mathrm{mol}^{-1}$, for compounds $\mathbf{1 a}, \mathbf{1 b}, \mathbf{2 a}$, and $\mathbf{2 b}$, respectively.

\subsection{Mössbauer spectroscopy}

Mössbauer spectra of complexes 1a and 1b samples were collected between 295 and $1.7 \mathrm{~K}$ in transmission mode using a conventional constant-acceleration spectrometer and a $25 \mathrm{mCi}$

${ }^{57} \mathrm{Co}$ source in a $\mathrm{Rh}$ matrix. The velocity scale was calibrated using $\alpha$-Fe foil. Isomer shifts, IS, are given relative to this standard at room temperature. The absorbers were obtained by gently packing the sample into a perspex holder inside a glovebox. Absorber thickness was calculated on the basis of the corresponding electronic mass-absorption coefficients for the $14.4 \mathrm{keV}$ radiation, according to Long et al. (1983) [36]. Low-temperature measurements between 1.7 and $4 \mathrm{~K}$ were performed with the sample immersed in liquid $\mathrm{He}$ and above $4 \mathrm{~K}$ in He exchange gas. The spectra were fitted to Lorentzian lines using a non-linear leastsquares method [37].

\section{Acknowledgements}

We thank Fundação para a Ciência e a Tecnologia, Portugal, for financial support (Projects UID/QUI/00100/2013 and UID/Multi/04349/2013) and for fellowships to T.F.C.C, C.A.F. 
and P.T.G. (PD/BD/52372/2013-CATSUS PhD Programme, SFRH/BPD/112340/2015, and SFRH/BSAB/ 140115/2018, respectively).

\section{References}

[1] (a) T. J. J. Sciarone, C. A. Nijhuis, A. Meetsma, B. Hessen, Dalton Trans. (2006) 4896; (b) S. C. Bart, E. J. Hawrelak, E. Lobkovsky, P. J. Chirik, Organometallics 24 (2005) 5518.

[2] Y. Rechkemmer, F. D. Breitgoff, M. van der Meer, M. Atanasov, M. Hakl, M. Orlita, P. Neugebauer, F. Neese, B. Sarkar, J. van Slageren, Nat. Commun. 7 (2016) 10467.

[3] W. H. Harman, T. D. Harris, D. E. Freedman, H. Fong, A. Chang, J. D. Rinehart, A. Ozarowski, M. T. Sougrati, F. Grandjean, G. J. Long, J. R. Long, C. J. Chang, Dalton Trans. 2007955.

[4] H. Hao, S. Bhandari, Y. Ding, Eur. J. Inorg. Chem. (2002) 1060.

[5] T. K. Panda, K. Yamamoto, K. Yamamoto, H. Kaneko, Y. Yang, H. Tsurugi, K. Mashima, Organometallics 31 (2012) 2268.

[6] D. M. Dawson, D. A. Walker, M. Thornton-Pett, M. Bochmann, J. Chem. Soc. Dalton Trans. (2000) 459.

[7] Y. Yoshida, S. Matsui, Y. Takagi, M. Mitani, T. Nakano, H. Tanaka, N. Kashiwa, T. Fujita, Organometallics 20 (2001) 4793.

[8] J.-S. Mu, Y.-X. Wang, B.-X. Li, Y.-S. Li, Dalton Trans. 40 (2011) 3490.

[9] V. C. Gibson, C. Newton, C. Redshaw, G. A. Solan, A. J. P. White, D. J. Williams, J. Chem. Soc. Dalton Trans. (2002) 4017.

[10] J. Li, H. Song, C. Cui, Appl. Organomet. Chem. 24 (2010) 82.

[11] C. S. B. Gomes, M. T. Duarte, P. T. Gomes, J. Organomet. Chem. 760 (2014) 167.

[12] R. M. Bellabarba, P. T. Gomes, S. I. Pascu, Dalton Trans. (2003) 4431.

[13] C. S. B. Gomes, P. T. Gomes, M. T. Duarte, R. E. Di Paolo, A. L. Maçanita, M. J. Calhorda, Inorg. Chem. 48 (2009) 11176.

[14] T. L. Poulos, Chem. Rev. 114 (2014) 3919.

[15] R. Banerjee, S. W. Ragsdale, Annu. Rev. Biochem. 72 (2003) 209.

[16] S. A. Carabineiro, L. C. Silva, P. T. Gomes, L. C. J. Pereira, L. F. Veiros, S. I. Pascu, M. T. Duarte, R. T. Henriques, Inorg. Chem. 46 (2007) 6880. 
[17] S. A. Carabineiro, R. M. Bellabarba, P. T. Gomes, S. I. Pascu, L. F. Veiros, C. Freire, L. C. J. Pereira, R. T. Henriques, M. C. Oliveira, J. E. Warren, Inorg. Chem. 47 (2008) 8896.

[18] C. A. C. Figueira, P. S. Lopes, C. S. B. Gomes, L. F. Veiros, P. T. Gomes, CrystEngComm 17 (2015) 6406-6419.

[19] (a) S. D. Reid, A. J. Blake, C. Wilson, J. B. Love, Inorg. Chem. 45 (2006) 636;

(b) J. A. Wolny, M. F. Rudolf, Z. Ciunik, K. Gatner, S. Wolowiec, J. Chem. Soc. Dalton Trans. (1993) 1611;

(c) B. S. Manhas, B. C. Verma, S. B. Kalia, Polyhedron 14 (1995) 3549;

(d) B. S. Jaynes, L. H. Doerrer, S. Liu, S. J. Lippard, Inorg. Chem. 34 (1995) 5735.

[20] (a) F. A. Cotton, G. Wilkinson, C. A. Murillo, M. Bochmann, Advanced Inorganic Chemistry; 6th ed., Wiley, 1999, pp.784 and 821;

(b) N. N. Greenwood A. Earnshaw, Chemistry of the Elements, 2nd ed., Elsevier Butterworth-Heinemann, 1997, pp.1092 and 1132.

[21] L. Yang, D. R. Powell, R. P. Houser, Dalton Trans. (2007) 955.

[22] (a) Y.-Z. Liu, J. Wang, Y. Zhao, L. Chen, X.-T. Chen, Z.-L. Xue, Dalton Trans. 44 (2015) 908;

(b) E. J. Hawrelak, W. H. Bernskoetter, E. Lobkovsky, G. T. Yee, E. Bill, P. J. Chirik, Inorg. Chem. 44 (2005) 3103.

(c) P.-H. Lin, N. C. Smythe, S. I. Gorelsky, S. Maguire, N. J. Henson, I. Korobkov, B. L. Scott, J. C. Gordon, R. T. Baker, M. Murugesu, J. Am. Chem. Soc. 133 (2011) 15806.

[23] O. Kahn, Molecular Magnetism, VCH Publishers Inc., New York, 1993, ch. 2, pp. 929.

[24] S. K. Langley, N. F. Chilton, B. Moubaraki, K. S. Murray, Dalton Trans. 40 (2011) 12201.

[25] S. Gomez-Coca, E. Cremades, N. Aliaga-Alcalde, E. Ruiz, J. Am. Chem. Soc., 135 (2013) 7010 .

[26] J. M. Zadrozny, J. R. Long, J. Am. Chem. Soc. 133 (2011) 20732.

[27] N. N. Greenwood, T. C. Gibb, Mössbauer Spectroscopy, Chapman and Hall, Ltd. Publishers, London, England, 1971.

[28] G. M. Bancroft, Mössbauer Spectroscopy: An Introduction for Inorganic Chemists and Geochemists, McGraw-Hill, London, 1973. 
[29] (a) D. F. Evans, J. Chem. Soc. (1959) 2003;

(b) S. K. Sur, J. Magnet. Res. 82 (1989) 169.

[30] SMART Software for the CCD Detector System Version 5.625, Bruker AXS Inc., Madison, WI, USA, 2001.

[31] SAINT Software for the CCD Detector System, Version 7.03, Bruker AXS Inc., Madison, WI, USA, 2004.

[32] G. M. Sheldrick, SADABS, Program for Empirical Absorption Correction, University of Göttingen, Göttingen, 1996.

[33] M. C. Burla, R. Caliandro, B. Carrozzini, G. L. Cascarano, C. Cuocci, C. Giacovazzo, M. Mallamo, A. Mazzone, G. Polidori, J. Appl. Cryst. 48 (2015) 306.

[34] L. J. Farrugia, J. Appl. Crystallogr. 32 (1999) 837.

[35] M. N. Burnett, C. K. Johnson, ORTEP-III: Oak Ridge Thermal Ellipsoid Plot Program for Crystal Structure Illustration, Oak Ridge National Laboratory, 1996. Report ORNL-6895.

[36] G. J. Long, T. E. Cranshaw, G. Longworth, Mossb. Effect. Ref. Data J. 6 (1983) 42.

[37] J. C. Waerenborgh, D. P. Rojas, A. L. Shaula, G. C. Mather, M. V. Patrakeev, V. V. Kharton, J. R. Frade, Mater. Lett. 59 (2005) 1644. 